\title{
ON THE ROLE OF CONSCIOUSNESS IN GOAL PURSUIT
}

\author{
Karin C. A. Bongers \\ University of Amsterdam and Behavioural Science Institute, \\ Radboud University Nijmegen \\ Ap Dijksterhuis \\ University of Amsterdam and Behavioural Science Institute, \\ Radboud University Nijmegen \\ Russell Spears \\ University of Amsterdam and Cardiff University
}

\begin{abstract}
Recent research has shown that goal pursuit can proceed unconsciously. That is, the entire process from goal activation to goal completion can take place without conscious awareness of the goal. This observation is somewhat paradoxical, because there is no denying that in daily life people are often consciously aware of the goals they pursue. The question is when and why? Here, we tested and confirmed the hypothesis that people become aware of their goals when goal pursuit is difficult. In two experiments, we demonstrated that unconsciously-activated goals are more likely to intrude into consciousness when goal progress is problematic.
\end{abstract}

Just as a stream flows smoothly on as long as it encounters no obstruction, so the nature of man and animal is such that we never really notice or become conscious of what is agreeable to our will; if we are to notice something, our will has to have been thwarted.

-Arthur Schopenhauer

Imagine you are presenting your work at a conference and your presentation meets with disaster. Your laptop crashes, your jokes fall flat, and a lot of people attending your presentation leave the room or fall asleep. Immediately after this horrible fiasco, thoughts about the goal you actually pursued, the goal of making an excellent, lasting impression on your colleagues, keeps intruding into consciousness.

\footnotetext{
We would like to thank Sara Jahfari, Hedde Rijkes, Edwina Romswinckel, and Thyra Pappot for collecting the data for Experiment 1 and we are grateful to Daphne V. Wiersema for her helpful contributions to Experiment 2.

Correspondence concerning this article should be addressed to Karin C.A. Bongers, Behavioural Science Institute, Radboud University Nijmegen, Department of Social and Cultural Psychology, Postbus 9104, 6500 HE Nijmegen, The Netherlands. E-mail: k.bongers@psych.ru.nl.
} 
In psychological terms, you became consciously aware of your goal-in this case making a good impression-when goal attainment became problematic.

Traditionally, theories on self-regulation have emphasized the role of conscious awareness in the process of goal pursuit. People generally assumed that we deliberately choose our goals, that we intentionally engage in goal-directed behavior and that progress toward goal-attainment is consciously evaluated (e.g., Bandura, 1981; Deci \& Ryan, 1985; Locke \& Latham, 1990). However, recently it has been shown that the process from goal activation to goal completion can ensue without conscious awareness (e.g., Bargh, 1990; Chartrand \& Bargh 1996; Fishbach, Friedman, \& Kruglanski, 2003). For example, participants primed with the goal to achieve performed better on an intellectual task than participants not primed with this goal, without primed participants ever being aware of their goal to achieve (Bargh, Gollwitzer, Lee-Chai, Barndollar, \& Trotschel, 2001). Furthermore, Aarts and colleagues (Aarts, Gollwitzer, \& Hassin, 2004) recently demonstrated goal contagion, the tendency for people to engage in unconscious goal pursuit merely because of other people in their environment are doing so. Finally, it has been shown that the activation of the representation of significant others can induce goal-directed behavior (Fitzsimons \& Bargh, 2003; Shah, 2003). For instance, among people who associate their father with the goal to achieve (i.e., their father wants to them to do well in life), subliminally priming with father was enough to activate the goal to achieve (Shah, 2003).

We think that the recent findings demonstrating that goal pursuit can proceed unconsciously points at an interesting paradox. After all, we are often consciously aware of our goals. We are sometimes aware of the fact that we want to achieve something, that we want to be polite, or that we want to make a good impression on other people. Hence, on the one hand we are faced with the observation that goal pursuit does not seem to need consciousness (at least under some circumstances), whereas on the other hand we know that we are frequently aware of our goals.

The question we want to address in the current research is when we become aware of our goals. We hypothesize, like Schopenhauer in our opening quote suggested, that one determinant of conscious awareness of goals is problematic goal pursuit. When (unconsciously activated) goals operate smoothly, no conscious awareness occurs. However, when goal pursuit becomes problematic, you do become aware of this goal. Below, we further elaborate on our hypothesis.

\section{PROBLEMATIC GOAL PURSUIT AND CONSCIOUS AWARENESS}

It may be noted that our hypothesis has been suggested before-by people other than Schopenhauer that is. According to Martin and colleagues (Martin \& Tesser, 1996; Martin, Tesser, \& McIntosh, 1993) thoughts concerning incomplete tasks or frustrated goals are persistent and powerful and will enter consciousness unintentionally. Moreover, it has been suggested that these intrusive thoughts are caused by heightened accessibility of goal-related concepts (e.g., see Rholes \& Pryor, 1982). When goal pursuit is problematic these thoughts are likely to keep intruding consciousness until the goal is either met or abandoned (e.g., Beckmann, 1998; Klinger, 1996). 
However, where more general theories would predict that problematic goal pursuit leads to conscious awareness of these goals, this idea has not been empirically tested. Moreover, it is also not clear how problematic goal pursuit could lead to conscious awareness. In what follows, we sketch the proposed underlying process.

\section{GOAL ACCESSIBILITY}

A major difference between priming a motivational and a nonmotivational mental representation is the strength of the priming effects over time. Perceptual (nonmotivational) priming effects are known to decrease in strength over time (e.g., Dijksterhuis \& Bargh, 2001; Higgins, Bargh, \& Lombardi, 1985), whereas effects of goal priming (motivational) are known to be able to increase in strength over time until the goal is attained (e.g., Atkinson \& Birch, 1970; Bargh et al., 2001; Chartand $\&$ Bargh, 2002). The increase in strength over time is due to enhanced accessibility of goal-related concepts, which is maintained as long as the goal is active and not yet attained (e.g., Custers \& Aarts, 2005; Förster, Liberman, \& Higgins, 2005; Goschke \& Kuhl, 1993; Marsh, Hicks, \& Bink, 1998).

The recent findings are reminiscent of the classic Zeigarnik Effect (Zeigarnik, 1938). In a typical empirical demonstration of this effect, participants are asked to work on a series of tasks until each task is completed. However, during some of the tasks participants are interrupted, and hence, they are not able to complete them. Afterwards participants are asked to recall the tasks they had worked on, and it is generally found that unfinished tasks are recalled much better than finished ones. Thus, interrupted tasks remained highly accessible and are more likely to be (consciously) remembered.

One should note, however, that the Zeigarnik-effect differs from our hypothesized effect in two respects. First, in studies on the Zeigarnik-effect, people recalled the tasks they had worked on and not the goals they had pursued (see also Beckmann, 1998). Furthermore, although the interrupted tasks were recalled much more often than finished ones, this happened only after people were asked to recall the tasks. Task-related thoughts did not intrude into consciousness spontaneously, as we propose happens with goal-related thoughts when goal pursuit is problematic.

To recapitulate, there is evidence showing that active goals enhance accessibility of goal-related concepts and that accessibility remains high until the goal is attained. The next question to address is whether this heightened accessibility indeed leads to conscious awareness.

\section{FROM ACTIVATION TO CONSCIOUS AWARENESS}

Recently, various researchers (Dehaene, Changeux, Naccache, Sackur, \& Sergent, 2006; Dijksterhuis \& Aarts, 2010; Koch \& Tsuchiya, 2006; Lamme, 2003) have emphasized the difference between consciousness and attention. The activation of a stimulus (this can be a percept but also a thought) is dependent on two processes: 
The first is a bottom-up process determined by objective stimulus properties. The second is a top-down process - that we call attention - that is determined by needs and goals. These processes jointly determine how strongly a percept or thought is activated, to what extent it will influence behavior, and whether a percept or thought will enter consciousness. When only one of the two processes is strong, a percept or thought often remains unconscious. For instance, sometimes a percept is quite salient, but lack of attention causes it to bypass consciousness altogether, as demonstrations of inattentional blindness or change blindness show (e.g., Mack \& Rock, 1998). Conversely, very subtle stimuli-such as primes in a laboratory situation-can influence our functioning because we pay attention to them while we encode them and this leads to sufficiently high activation levels (see e.g., Pessiglione et al., 2007). Once a stimulus has become active either because of salience or because of attention during encoding, it can remain active for quite a while, even when the stimulus is not very salient anymore and/or attention is relatively low. However, such an active but unconscious stimulus may enter consciousness if an additional bottom-up or top-down process increases activation levels even further.

Goal priming is such a case. The prime itself is subtle but attention during encoding is sufficient for the goal to be activated. It remains unconscious however, until either a bottom-up or a top-down process increases activation further so that it enters consciousness (Dehaene et al., 2006; Lamme, 2003). Encountering something that makes goal pursuit problematic - such as a presentation that meets with disaster-evokes such an additional process, thereby increasing the probability of the goal to pop into consciousness. In two experiments, we investigate our hypothesis that people start to think consciously about unconsciously, activated goals when goals are difficult to attain.

\section{EXPERIMENT 1}

\section{METHOD}

Participants and Design. One hundred (25 men, 75 women) Dutch undergraduate students at the University of Amsterdam were randomly assigned to one of the cells in a 2 (goal: achievement vs. no goal) x 2 (task: 12 minutes vs. 3 minutes) between participants design, receiving either course credits or money $(€ 4)$.

Procedure and Materials. Participants started with a lexical decision task, which was announced as a "language task." They were subliminally primed with words related to the goal to achieve (e.g., to win and to attain) or with neutral words (e.g., to use and to drag). These words were flashed on the screen for 17 milliseconds, preceded by forward mask for 250 milliseconds (a row of $X$ s) and followed by a backward mask (again a row of X s) for 33 milliseconds. Immediately after the backward mask a word was presented on the screen. Participants were asked to indicate as quickly and as accurately as possible whether the word on the screen was an existing Dutch word or not by pressing respectively the $\mathrm{c}$ or the $\mathrm{m}$ on the computer keyboard. Fourteen words were existing Dutch words and fourteen words were nonsense words, making a total of 28 trials.

The second task was a memory game. Eighteen pairs of cards with identical images were presented in a grid of six cards by six cards with the images invisible for 
participants. Participants were asked to find all the pairs by selecting two cards in each trial. The images were then shown and if they were identical the cards disappeared. If they were not identical the images flipped back into being invisible. The difficulty of goal attainment was manipulated by giving participants either a maximum of 3 minutes to complete it, which was too short to complete the game, or a maximum of 12 minutes, which was more than enough time to complete the game.

After the memory game and a brief break, conscious thoughts were measured in a sentences completion test. We asked participants to complete the sentences with the first thing that came to mind. The following sentences were used in sequential order: I . . , I am . . . I feel . . . I wished . . . I tried . . . The memory game ..., During the memory game I wanted to ..., During the memory game I tried to ... The first six sentences were presented three times and the last two sentences were presented only once. Two independent raters who were blind for conditions coded all twenty sentences into either goal-related thoughts or no-goal-related thoughts $(\kappa=.85, p<.001)$. Goal-related thoughts are thoughts referring to the goal to achieve (e.g., I tried to do my best at the memory game) and no-goal-related thoughts are all other thoughts. To measure conscious goal-related thoughts, scores were computed by averaging the number of goal-related thoughts as coded by the two raters.

Finally, participants were thoroughly debriefed. The funneled debriefing indicated that none of the participants was aware of the relationship between the different parts of the experiment. However, the debriefing indicated that ten participants saw flashes during the lexical decision task. Data from these participants were excluded, because for these participants it cannot be guaranteed that goal activation was unconscious. One participant gave more than $20 \%$ incorrect responses in the lexical decision task. Data from this participant were also excluded, because it cannot be guaranteed that she followed our instructions.

\section{RESULTS}

Performance. It was confirmed that all participants in the 12 minutes conditions, but none of the participants in the 3 minutes conditions, completed the memory game within the time given. Indeed, in the 12 minutes conditions everyone found all the 36 cards of the memory game, while in the 3 minutes condition none of the participants found all the 36 cards of the memory game $(M=13.51, S D=6.97)$, resulting in a main effect of task, $F(1,85)=450.45, p<.001, \eta_{\mathrm{p}}{ }^{2}=.84$. No effects of goal emerged. ${ }^{1}$

Conscious Thoughts. To test our prediction that participants who experienced difficulty attaining their unconsciously activated achievement goal would report more conscious goal-related thoughts compared to participants in all other 3 conditions, we conducted a planned comparison analysis. The results indeed showed

\footnotetext{
1. Based on previous research (Bongers, Dijksterhuis, \& Spears, 2009) we suggest that primes may have a weaker influence on both very easy and very difficult trials. However, since one may doubt the potency of our achievement goal manipulation, we conducted a pilot study with the same goal prime manipulation, but with moderately difficult RAT trials. In that study we indeed demonstrated that participants primed with an achievement goal gave more correct solutions to the RAT trials than participants not primed with that goal.
} 
TABLE 1. Conscious Thoughts as a Function of Experimental Condition (Experiment 1)

\begin{tabular}{lcc}
\hline & & Goal \\
\cline { 2 - 3 } Memory game & Achievement & Control \\
\hline Easy & & \\
$M$ & 2.03 & 2.44 \\
$S D$ & $(0.97)$ & $(0.74)$ \\
Difficult & & \\
$M$ & 3.11 & 2.33 \\
$S D$ & $(1.79)$ & $(0.91)$ \\
\hline
\end{tabular}

Note. Values are the total number of reported conscious thoughts.

that participants in the goal-3 minutes condition reported more conscious thoughts about the goal to achieve than participants in the other 3 conditions, $F(1,85)=8.80$, $p<.01, \eta_{\mathrm{p}}^{2}=.09$, see Table 1 .

One alternative interpretation for the findings that participants in the goal-3 minutes condition reported more conscious goal-related thoughts than participants in the 12 minutes conditions is that these latter participants may not have seen the task as relevant for the goal to achieve, due to the ease of the task. To rule out this alternative interpretation we contrasted the total number of conscious goal-related thoughts between the two 3 minutes conditions. This analysis demonstrated that participants in the goal- 3 minutes condition reported more conscious goal-related thoughts than participants in the no goal-3 minutes condition, $F(1,85)$ $=5.13, p<.05, \eta_{\mathrm{p}}{ }^{2}=.06$. These findings indicate that participants who failed to attain their unconsciously-activated goals not only reported more conscious goalrelated thoughts than participants in the 12 minutes conditions, but also more than participants in the other 3 minutes condition. Therefore, the relevance interpretation seems to be not a very likely alternative. In sum, the findings of Experiment 1 demonstrated an enhancement of the number of conscious thoughts about the goal when goal attainment is difficult.

\section{EXPERIMENT 2}

The findings of Experiment 1 support the idea that people will consciously think about unconsciously-activated goals when these goals become difficult to pursue. However, one may remark that the dependent variable used in Experiment 1 is an accessibility measure rather than a true measure of contents of consciousness. Therefore, in Experiment 2 conscious thoughts were measured online with a thinkaloud protocol. After being primed with an achievement goal or not, participants were given a RAT (Mednick, 1962) that was either difficult or easy, making goal attainment problematic or easy, respectively. Participants were encouraged to say everything they were thinking about out loud, regardless of the relation to the task. No more instructions were given. If participants spontaneously report conscious thoughts about the goal to achieve during the test, without receiving any cues to do so, we can conclude that we are indeed measuring conscious thoughts and not cognitive accessibility of goal-related constructs. We expected that participants 
primed with the goal to achieve and who performed the difficult test would report more conscious goal-related thoughts than participants in all other conditions.

\section{METHOD}

Participants and Design. Sixty-five (25 men, 40 women) Dutch undergraduate students at the University of Amsterdam were randomly assigned to one of the cells of a 2 (goal: achievement vs. no goal) x 2 (task: easy vs. difficult) between participants design, receiving either course credits or money $(€ 4)$.

Procedure and Materials. Participants started with a Dutch version of the RAT as a practice task. We chose five fairly easy trials from the pilot test (percentage correct: $72 \%$ ). During this task, participants were asked to verbalize their thoughts and think out loud, regardless of whether their thoughts were task-relevant or not. All thoughts participants reported during this task were tape-recorded.

The second task was the same lexical decision task as used in Experiment 1. After the lexical decision task, participants again solved trials of the RAT. It was again emphasized that they should say everything they were thinking about out loud. To manipulate the difficulty of the task, ten difficult associations (percentage correct: $15 \%$ ) and ten easy associations (percentage correct: 74\%) were selected. Half of the participants were given the easy associations, the other half were given the difficult associations. As in Experiment 1, we did not expect any differences as a function of goal prime. All thoughts were tape-recorded.

Two independent raters who were blind to condition coded all conscious thoughts. The thoughts were either categorized as task-related thoughts (e.g., i.e., rehearsal of the three given words, or searching for synonyms), or as goal-related thoughts (e.g., I want to do this well or I think I am going to be good at this ), or as irrelevant thoughts (e.g., Shopping would be great now). Due to huge differences in total number of thoughts participants reported, all thoughts were computed as percentages of the total number of thoughts a participant had during the task. The interrater agreement was high $(r=.97$ for task-related thoughts, $r=.98$ for irrelevant thoughts, and $r=.90$ for goal-related thoughts) and the scores of the raters were averaged.

Funneled debriefing indicated that none of the participants was aware of the relationship between the lexical decision task and the RAT. However, one participant reported seeing flashes during the lexical decision task. Data from this participant were excluded, because it cannot be guaranteed that goal activation was unconscious. Seven participants gave more than $20 \%$ incorrect responses in the lexical decision task. Data from these participants were excluded, because these participants probably did not follow our instructions.

\section{RESULTS}

Performance. Participants in the easy conditions gave more correct solutions of RAT trails $(M=8.07, S D=1.96)$ than participants in the difficult conditions, $(M=$ $1.11, S D=1.12), F(1,53)=255.25, p<.001, \eta_{\mathrm{p}}{ }^{2}=.83$. Like Experiment 1 , no effects of goal emerged. 
Conscious Thoughts. To see whether failure to attain an unconsciously activated achievement goal led to more conscious goal-related thoughts, we conducted a planned comparison. The analysis confirmed that participants with a goal and difficult RAT items reported more conscious goal-related thoughts than participants in the other three conditions, $F(1,53)=9.29, p<.01, \eta_{\mathrm{p}}{ }^{2}=.15$, see Table 2 . To test whether participants in the goal-difficult condition reported more conscious goal-related thoughts than participants in the no goal-difficult condition we contrasted the number of goal-related thoughts between the two difficult conditions. The analysis showed that the difference between the goal-difficult condition and the no goal-difficult condition was marginally significant, $F(1,53)=3.59, p=.064$, $\eta_{\mathrm{p}}^{2}=.06$.

The task-related thoughts and the irrelevant thoughts were subjected to two separate 2 (goal: achievement vs. no goal) x 2 (task: easy vs. difficult) between-participants analyses of variance (ANOVA). The analyses showed that participants in the difficult conditions thought more about the task than participants in the easy conditions $(M=76.95, S D=14.56$ and $M=67.71, S D=20.46$, respectively), $F(1,53)$ $=3.99, p=.05, \eta_{\mathrm{p}}{ }^{2}=.07$, and that participants in the easy conditions thought more about irrelevant things than participants in the difficult conditions $(M=28.29, S D$ $=19.47$ and $M=15.75, S D=12.39$, respectively), $F(1,53)=8.51, p<.01, \eta_{\mathrm{p}}{ }^{2}=.14$.

In sum, we replicated our findings of Experiment 1 with a different dependent variable that measured the number of conscious goal related thoughts online.

\section{DISCUSSION}

People start to think consciously about unconsciously, activated goals when goal progress is problematic. In Experiment 1 we showed that participants primed with an achievement goal reported the highest number of goal-related thoughts after performing the 3 minutes memory game compared to participants in all other conditions. In Experiment 2 we replicated these findings with an online measure of conscious goal-related thoughts and a difficult vs. easy goal task. In both experiments we did not find any effects of goal priming on performance. ${ }^{1}$

\section{FUTURE DIRECTIONS}

In future research, we need to explore whether conscious awareness of a goal in the face of difficulty serves a self-regulatory function or whether it is merely an irrelevant epiphenomenon (or whether it is even detrimental for goal pursuit; see also, Bongers \& Dijksterhuis, 2009). It is highly likely that it depends on many different factors whether conscious awareness of a goal is helpful or not. For example, the effort it takes to engage in goal-directed behavior and the expectancies people have about goal-attainment may moderate the effects of conscious awareness on subsequent goal pursuit.

Another important factor that can potentially moderate the effects of conscious awareness of a goal on subsequent goal pursuit is the cognitive resources it takes 
TABLE 2. Conscious Thoughts as a Function of Experimental Condition (Experiment 2)

\begin{tabular}{lrr}
\hline & \multicolumn{1}{c}{ Goal } & \\
\cline { 2 - 3 } RAT & Achievement & Control \\
\hline Easy & & 4.52 \\
$M$ & 3.21 & $(2.92)$ \\
$S D$ & $(4.09)$ & \\
Difficult & & 5.52 \\
$M$ & 9.12 & $(5.38)$ \\
$S D$ & $(7.67)$ & \\
\hline
\end{tabular}

Note. Values are the number conscious thoughts in percentages of total reported thoughts.

to think about the goal. That is, consciously thinking about goal pursuit failure may use up cognitive resources that are needed for engaging in goal-directed behavior in the first place (e.g., Martin \& Tesser, 1996; Kuhl, 1981). More research is necessary to explore conditions under which consciously thinking about goals that are difficult to attain will be helpful and under which circumstances it will not be helpful for subsequent goal pursuit.

Finally, other types of problematic goal pursuits need to be explored. We manipulated problematic goal pursuit with amount of time (Experiment 1) and task difficulty (Experiment 2). However, goal pursuit can also be problematic by disruptions, hindrances, or obstacles, etc. We expect such causes of problematic goal pursuit to result in the same effects as we found.

\section{CONCLUSIONS}

In many situations people pursue goals of which they are not aware. In fact, recent research shows that the entire process, from goal-activation to goal-completion, can operate without conscious awareness (Bargh, 1990; Chartrand \& Bargh, 1996; Fishbach, Friedman, \& Kruglanski, 2003). This sounds paradoxical, as there is no denying that we are often consciously aware of our goals. In the present work, we aimed to solve this paradox by examining when people become aware of their goals. We identified one factor that predicts whether people become aware of their goals: The difficulty to attain it. As Schopenhauer already argued a long time ago, when the going gets tough, the tough become aware. 


\section{APPENDIX}

Examples of RAT Trials Used in Experiment 2

\begin{tabular}{llll}
\hline Practice trials & cold & dark \\
wine & book & world & $\begin{array}{l}\text { answer: cellar } \\
\text { answer: atlas }\end{array}$ \\
maps & & blue & \\
pasy trials & stain & walking & answer: ink \\
toe & shoe & & answer: foot \\
Difficult trials & & hot & answer: tea \\
leaves & thirsty & red & answer: mouth \\
corner & talking & &
\end{tabular}

\section{REFERENCES}

Aarts, H., Gollwitzer, P. M., \& Hassin, R. R. (2004). Goal contagion: Perceiving is for pursuing. Journal of Personality and Social Psychology, 87, 23-37.

Atkinson, J. W., \& Birch, D. (1970). The dynamics of action. Oxford: John Wiley.

Bandura, A. (1981). In search of pure unidirectional determinants. Behavior Therapy, 12, 30-40.

Bargh, J. A. (1990). Auto motives: Preconscious determinants of social interaction. In R. M. Sorrentino \& E. T. Higgins (Eds), Handbook of motivation and cognition: Foundations of social behavior (Vol. 2, pp. 93-130). New York: Guilford Press.

Bargh, J. A., Gollwitzer, P. M., Lee Chai, A., Barndollar, K., \& Trotschel, R. (2001). The automated will: Nonconscious activation and pursuit of behavioral goals. Journal of Personality and Social Psycholo$g y, 81,1014-1027$.

Beckmann, J. (1998). Intrusive thoughts, rumination, and incomplete intentions. In M. Kofta, G. Weary, \& G. Sedek (Eds.), Personal control in action: Cognitive and motivational mechanisms. New York: Springer.

Bongers, K. C. A., \& Dijksterhuis, A. (2009). Consciousness as a trouble shooting device? The role of consciousness in goalpursuit. In E. Morsella, J. A. Bargh, \& P. Gollwitzer (Eds.), The Oxford handbook of human action (pp. 589-604). New York: Oxford University Press.
Bongers, K. C. A., Dijksterhuis, A., \& Spears, R. (2009). Self-esteem regulation after success and failure to attain unconsciously activated goals. Journal of Experimental Social Psychology, 45, 468-477.

Chartrand, T. L., \& Bargh, J. A. (1996). Automatic activation of impression formation and memorization goals: Nonconscious goal priming reproduces effects of explicit task instructions. Journal of Personality and Social Psychology, 71, 464-478.

Chartrand, T. J., \& Bargh, J. A. (2002). Nonconscious motivations: Their activation, operation, and consequences. In D. A. Stapel \& A. Tesser (Eds.), Self and motivation: Emerging psychological perspectives. (p. 226). Washington, DC: American Psychological Association.

Custers, R., \& Aarts, H. (2005). Positive affect as implicit motivator: On the nonconscious operation of behavioral goals. Journal of Personality and Social Psychology, 89, 129-142.

Deci, E. L., \& Ryan, C. S. (1985). Intrinsic motivation and self-determination in human behavior. New York: Plenum.

Dehaene, S., Changeux, J. P., Naccache, L., Sackur, J., \& Sergent, C. (2006). Conscious, preconscious, and subliminal processing: A testable taxonomy. Trends in Cognitive Sciences, 10(5), 204-211.

Dijksterhuis, A., \& Aarts, H. (2010). Goals, attention, and (un)consciousness. Annual Review of Psychology, 61, 467-490. 
Dijksterhuis, A., \& Bargh, J. A. (2001). The perception-behavior expressway: Automatic effects of social perception on social behavior. In M. P. Zanna (Ed.), Advances in experimental social psychology (Vol. 33, pp. 1-40). San Diego: Academic Press.

Fishbach, A., Friedman, R. S., \& Kruglanski, A. W. (2003). Leading us not unto temptation: Momentary allurements elicit overriding goal activation. Journal of Personality and Social Psychology, 84, 296-309.

Fitzsimons, G. M., \& Bargh, J. A. (2003). Thinking of you: Nonconscious pursuit of interpersonal goals associated with relationship partners. Journal of Personality and Social Psychology, 84, 148-164.

Förster, J., Liberman, N., \& Higgins, E. T. (2005). Accessibility from active and fulfilled goals. Journal of Experimental Social Psychology, 41, 220-239.

Goschke, T., \& Kuhl, J. (1993). Representation of intentions: Persisting activation in memory. Journal of Experimental Psychology: Learning, Memory, and Cognition, 19, 1211-1226.

Higgins, E. T., Bargh, J. A., \& Lombardi, W. J. (1985). Nature of priming effects on categorization. Journal of Experimental Psychology: Learning, Memory, and Cognition, 11, 59-69.

Klinger, E. (1996). The contents of thoughts: Interference as the downside of adaptive normal mechanisms in thought flow. In I. G. Sarason, G. R. Pierce, \& B. R. Sarason (Eds.), Cognitive interference. Theories, methods, and findings (pp. 3-23). Mahwah, NJ: Lawrence Erlbaum Associates.

Koch, C., \& Tsuchiya, N. (2006). Attention and consciousness: Two distinct brain processes. Trends in Cognitive Sciences, 11, 16-22.

Kuhl, J. (1981). Motivational and functional helplessness: The moderating effect of state versus action orientation. Journal of Personality and Social Psychology, 40, 155-170.

Lamme, V. A. F. (2003). Why visual attention and awareness are different. Trends in Cognitive Sciences, 7, 12-18.
Locke, E. A., \& Latham, G. P. (1990). A theory of goal setting and task performance. Englewood Cliffs, NJ: Prentice-Hall.

Mack, A., \& Rock, I. (1998). Inattentional blindness. Cambridge, MA: MIT Press.

Marsh, R. L., Hicks, J. L., \& Bink, M. L. (1998). Activation of completed, uncompleted, and partially completed intentions. Journal of Experimental Psychology: Learning, Memory and Cognition, 24, 350-361.

Martin, L. L., \& Tesser, A. (1996). Some ruminative thoughts. In R. S. Wyer (Ed.), Ruminative thoughts (pp.1-47). Hillsdale, NJ: Lawrence Erlbaum Associates.

Martin, L. L., Tesser, A., \& McIntosh, W. D. (1993). Wanting but not having: The effects of unattained goals on thoughts and feelings. In D. M. Wegner \& J. W. Pennebaker (Eds.), Handbook of mental control (pp. 552-572). Englewood Cliffs, NJ: Prentice-Hall.

Mednick, S. A. (1962). The associative basis of the creative process. Psychological Review, 69, 220-232.

Pessiglione, M., Schmidt, L. Draganski, B., Kalisch, R., Lau, H., Dolan, R. J., et al. (2007). How the brain translates money into force: A neuroimaging study of subliminal motivation. Science, 316, 904-906.

Rholes, W. S., \& Pryor, J. B. (1982). Cognitive accessibility and causal attributions. Personality and Social Psychology Bulletin, 8, 719-727.

Shah, J. (2003). Automatic for the people: How representations of significant others implicitly affect goal pursuit. Journal of Personality and Social Psychology, 84, 661-681.

Zeigarnik, B. (1938). On finished and unfinished tasks. In W. D. Ellis (Ed.), A source book of gestalt psychology (pp. 300-314). New York: Harcourt, Brace, \& World. (Reprinted and condensed from Psychologische Forschung, 1927, 9, 1-85.) 